\title{
Performance level analyses of public transportation using importance-performance analysis method
}

\author{
NursyamsuHidayat ${ }^{1 *}$ \\ ${ }^{1}$ Civil Engineering Diploma Program, Vocational School, GadjahMada University, Indonesia
}

\begin{abstract}
Yogyakarta, one of the middle cities in Indonesia, has been developing BRT system named Trans Jogja to reduce growth of motorization. However, the performance tends to decrease year by year, therefore the system and management upgrading must be carried out continuously to restore public trust. This research tries to investigate public satisfaction, their expectation, and some attributes considered important based on public's perspective using IPA method that can be used as useful information systems to evaluate service quality by prioritizing or focusing on areas where improvement is needed. The results reveal that decision maker must focus and allocate their resources to improve Trans Jogja system on the following attributes: a) keep punctuality, b) shorten waiting time in the bus stop, c) improve bus comfort, d) provide safety for child passenger, e) improve bus stop comfort, f) create new bus route to enlarge accessibility, and g) shorten bus travel time.
\end{abstract}

\section{Introduction}

Most of the cities in developing countries have been facing big problem with the public transportation. Also, Indonesian people tend to use private vehicle rather than public transportation. Along with increasing of welfare, economic growth, and easiness of buying private car, the motorization is increasing rapidly. On the other side, quality of public transport serviceability tends to decrease year by year. Yogyakarta, one of the middle cities in Indonesia, is facing the same problems of domination of private cars on the roadways and therefore improvement of public transportation serviceability must be carried out.

Idris [1] conducted the study on city bus in Yogyakarta, using Customer Satisfaction Index (CSI) the study revealed that the performance of bus system is quite poor. Bus operator must pay much attention in some indicators related to passenger's safety and comfort. Factors related to bus availability and punctuality are considered important based on passenger point of view.

At the same time, Yogyakarta local government has established a new system Bus Rapid Transyt (BRT), named Trans Jogja, for around 12 years to provide an alternative of public transportation for the residents. At first, the Trans Jogja level of service is rated very high by the public. However, public's expectation on Trans Jogja services is increasing year by year. In addition, increasing of the number of passengers is insignificant. Performance upgrading must be undertaken continuously to attract more users. This research tries to investigate public satisfaction, their expectation, and determine attributes considered important on Trans Jogja performance based on passenger and non passenger point of view.

\section{Methodology}

\subsection{Study Design}

In this study, interviewing survey was undertaken to Trans Jogja passenger and non-passenger. As a result, 200 passengers and 200 non-passengers are taken as respondents during data collection process in Yogyakarta. Data collections are conducted in October 2014.

Non-passenger respondents are chosen from the respondent that never or rarely using BRT, and nonregular passenger. They have their own car or motorcycle as main mode of transportation.

\subsection{Questionnaire}

A set of survey questionnaire is designed based on literature review. The first part of the questionnaire measures passenger/non-passenger characteristics. Respondent's socioeconomic and travel characteristics are also gathered, covering gender, age, occupational status, monthly transportation cost, and education level. The second part of the survey asks respondent's perception about trip characteristics, trip frequency, origin and destination, and trip purpose. The third part is divided into two sub-parts to covers respondent's perception on Trans Jogja performance and importance. A five-point Likert scale is used for both sub-parts with

\footnotetext{
*Corresponding author: nursyamsu.h@ugm.ac.id
} 
"one" representing very unsatisfied and "five" representing very satisfied for BRT performance and "one" representing very unimportant and "five" representing very important for BRT importance level.

Respondents characteristic can be declared firstly as follow: passenger respondent's characteristics of BRT Trans Jogja are elaborated based on gender and occupation. The percentage of female passenger is greater than male (51\% vs. $49 \%$, respectively). Most of the passenger respondents are students $(42 \%)$ and private sector worker $(23 \%)$, the remains are government employee $(11 \%)$, housewife $(10 \%)$, self-employed $(7 \%)$, pensioner $(2 \%)$, and jobless $(5 \%)$.

For the non-passenger respondents, male respondent are dominant $(58 \%)$ compare to female $(42 \%)$. Based on the occupation, it can be elaborated as students (49\%), self-employed $(15 \%)$, private sector worker $(16 \%)$, government employee (9\%), housewife $(5 \%)$, pensioner $(1 \%)$, and jobless $(5 \%)$.

Besides that, trip characteristics are captured in terms of monthly transport cost, trip frequency, and trip purpose.

\subsection{Analytical Tools}

Importance-Performance Analysis (IPA) is a statistical method to compare between performance/service experienced by user and level of satisfaction that their intended [2]. The first step of the IPA is the questionnaire establishment to investigate level of importance and performance in a five-point Likert scale.

Importance and performance analysis reveal level of suitability among level of importance and present service performed by producer. Level of suitability is comparison among scores of performance and importance of the product, therefore by this instrument could be determined priorities rank to agree with the user suitability/expectation as can be performed by following formula,

$$
\begin{aligned}
& T_{k}=\frac{x}{y} 100 \% \\
& \bar{x}=\frac{\sum x}{n} \\
& \bar{y}=\frac{\sum y}{n}
\end{aligned}
$$

where,

$$
\mathrm{Tk}=\text { level of suitability }
$$

$\mathrm{x} \quad=$ score of performance provided by producer

$\mathrm{y} \quad=$ score of importance by users

$\bar{x} \quad=$ average scores of performance

$\overline{\mathrm{y}} \quad=$ average scores of importance

$\mathrm{n} \quad=$ total respondents

Wong et al. [3] stated that the two dimensional IPA model is divided into four quadrants with performance on the $\mathrm{x}$-axis and importance on the $\mathrm{y}$-axis. As a result of this, four quadrants are created. The quadrants can be used to generate suggestions for BRT operator by differentiating between them.

1. Quadrant I (High Importance/Low Performance). Attributes that fall into this quadrant represent key areas that need to be improved with top priority.

2. Quadrant II (High Importance/High Performance). All attributes that fall into this quadrant are the strength and pillar of the organizations, and they should be the pride of the organizations.

3. Quadrant III (Low Importance/Low Performance). Thus, any of the attributes that fall into this quadrant are not important and pose no threat to the organizations.

4. Quadrant IV (Low Importance/High Performance. It denotes attributes that are overly emphasized by the operator; therefore, operator should reflect on these attributes, instead of continuing to focus in this quadrant, they should allocate more resources to deal with attributes that reside in quadrant I.

Above explanations can be resumed in Figure 1 that shows IPA grid.

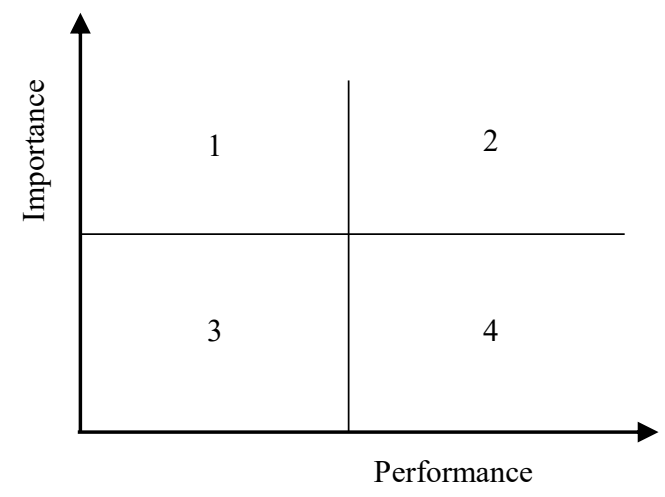

Fig. 1.The IPA Framework

The IPA evaluation tool can help to evaluate BRT attributes and to provide guidance to formulate BRT system strategy to allocate resources accurately to maximise a high advantage. The IPA model is used to evaluate the level of importance citizens attach to each of the attributes and also to examine the level of satisfaction perceived by them in the delivery of those attributes.

\section{Importance Performance Analyses of Trans Jogja Based on Passenger's Perception}

The amounts of 200 passengers are chosen to reveal suitability level from comparing between Trans Jogja performance score and passenger's importance score. Based on suitability level, it can be established the rank of attributes improvement to agree with passenger satisfaction. The mean importance for all the 19 attributes was rated 4.273 , whereas the mean satisfaction was just an average of 3.226. Therefore, if we were to plot the importance and performance on the IPA grid Trans Jogja leaders and managers would be able to quickly identify areas in which operators should allocate their resources to improve Trans Jogja performance. This is reflected in the IPA shown in Table 1 and Figure 2. 
Table 1.IPA Analyses of Trans Jogja Passenger

\begin{tabular}{|c|l|c|c|c|}
\hline \multirow{2}{*}{ Variables } & \multicolumn{1}{|c|}{ Attributes } & \multicolumn{2}{|c|}{ Mean } & \multirow{2}{*}{ Quadrant } \\
\cline { 3 - 4 } & & Performance & Importance & \\
\hline 1 & Walking distance to bus stop & 3.345 & 4.100 & 4 \\
\hline 2 & Easiness to buy the ticket & 3.915 & 4.155 & 4 \\
\hline 3 & Ticket price & 3.825 & 4.135 & 4 \\
\hline 4 & $\begin{array}{l}\text { Availability of time table, bus route } \\
\text { in the bus stop }\end{array}$ & 3.395 & 4.440 & 2 \\
\hline 5 & Bus stop comfort & 3.030 & 4.460 & 1 \\
\hline 6 & Waiting time in the bus stop & 2.720 & 4.345 & 1 \\
\hline 7 & Bus-stop'screw service & 3.535 & 4.080 & 4 \\
\hline 8 & Bus stop cleanliness & 3.230 & 4.275 & 2 \\
\hline 9 & Keepingpunctuality & 2.690 & 4.495 & 1 \\
\hline 10 & On buscomfort & 2.915 & 4.385 & 1 \\
\hline 11 & Bus crew service & 3.585 & 4.145 & 4 \\
\hline 12 & Secure from crime & 3.725 & 4.610 & 2 \\
\hline 13 & Trip safety & 3.470 & 4.645 & 2 \\
\hline 14 & Travel time & 2.935 & 4.310 & 1 \\
\hline 15 & Route/bus transfer & 3.205 & 4.015 & 3 \\
\hline 16 & Operating time & 3.415 & 4.080 & 4 \\
\hline 17 & Accessibility & 2.920 & 4.300 & 1 \\
\hline 18 & $\begin{array}{l}\text { Governmentinstantiate by using } \\
\text { public transportation }\end{array}$ & 2.535 & 3.870 & 3 \\
\hline 19 & Safe for childpassenger & 2.900 & 4.335 & 1 \\
\hline & Total & 61.290 & 81.180 & \\
\hline & Mean & 3.226 & 4.273 & \\
\hline
\end{tabular}

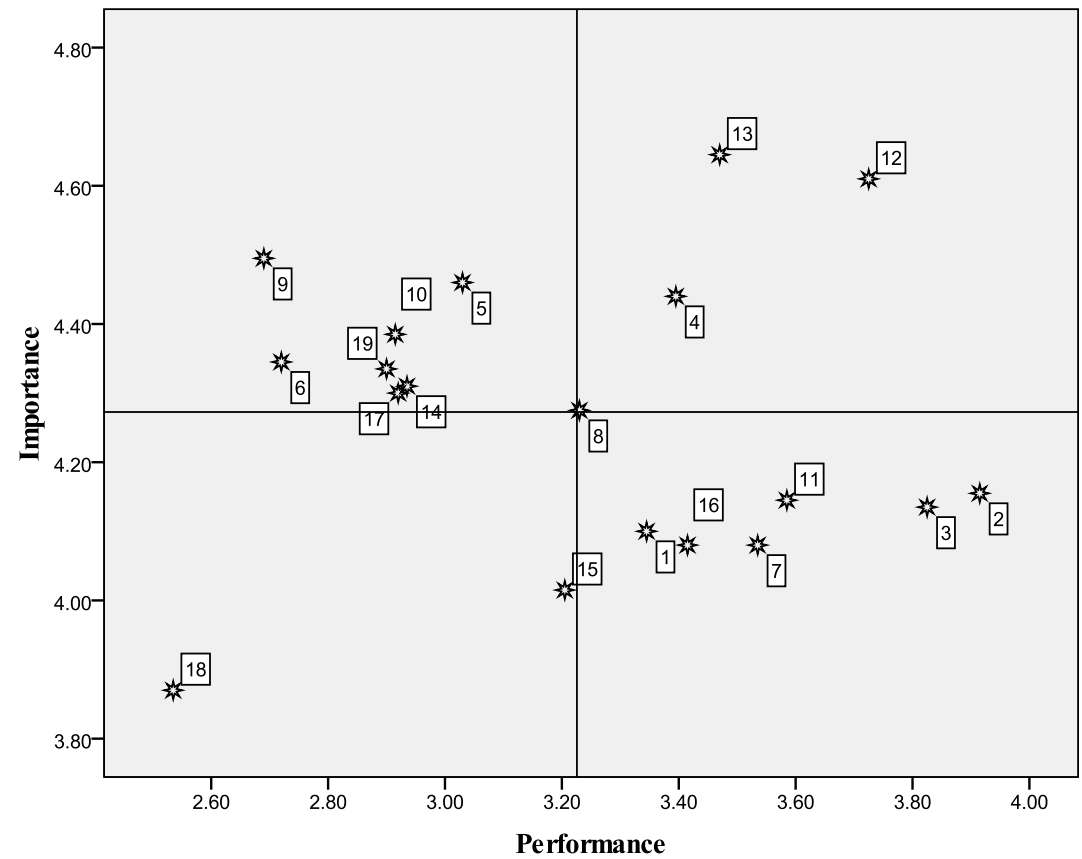

Fig. 2.Trans Jogja Passenger IPA Grid

The intersection in the IPA is made available using the mean level of importance at 4.273 and the mean level of performance 3.226. In quadrant I, passengers perceive the attributes as very important, but the perceptions of Trans Jogja performance levels are below average. Thus, further improvement efforts should be concentrated here. There are seven attributes that fall into this quadrant.

1. Keeping punctuality (9)
2. Waiting time in the bus stop (6)

3. On bus comfort (10)

4. Safe for child passenger (19)

5. Bus stop comfort (5)

6. Accessibility (17)

7. Travel time (14)

Waiting time in the bus stop and bus punctuality are the two main parameters to attract BRT user. Because 
previous bus system in the city is lack in reliability in terms of punctuality, waiting time, and comfort as well.

However, some attributes are important to build passengers' trust in using Trans Jogja. These attributes have already well done and must be kept in high level performance because passengers satisfy with the recent performance. Attributes such as availability of time table, bus route in the bus stop (4), bus stop cleanliness (8), secure from crime (12), and trip safety (13), situated in quadrant II, are perceived to be very important and satisfied from the passenger's perspective. All these attributes are the strengths of the Trans Jogja operation and the bus's operator should keep up the good work in maintaining or delighting their passengers, as otherwise, these benefits might risk falling into the first quadrant.

Some of the attributes that literally categorized as low priority in quadrant III are route/bus transfer (15) and government instantiate by using public transportation (18).

In quadrant IV, there are six attributes namely, walking distance to bus stop (1), easiness to buy the ticket (2), ticket price (3), bus-stop's crew service (7), bus crew service (11), and operating time (16) that are rated by passengers as of low importance with high performance. Here, the passengers are very satisfied with these Trans Jogja attributes performance, but all the continuous effort in delivering those attributes to the passenger will be futile if passengers are already satisfied. Therefore, present efforts on these attributes in this quadrant are overstated and Trans Jogja operators should consider allocating resources (i.e., money, effort, and time) elsewhere, especially on those attributes in the first quadrant, to yield a higher benefits and performance.

\section{Importance Performance Analyses of Trans Jogja Based on Non Passenger's Perspective}

Two hundred citizens are sampled as non-passenger respondents for gathering their perception on Trans Jogja performance. Also, their expectation are needed to identify attributes must be improved for possibility to attract new comer passengers. Based on non-passenger point of view, IPA analyses can find some attributes which need improvement to correspond with their satisfaction. The mean importance for all the 19 attributes was rated 4.113 , whereas the mean satisfaction was just an average of 2.902. This is reflected in the IPA shown in Table 2 and Figure 3.

Table 2.IPA Analyses of Trans Jogja Non-Passenger

\begin{tabular}{|c|l|c|c|c|}
\hline \multirow{2}{*}{ Variables } & \multicolumn{1}{|c|}{ Attributes } & \multicolumn{2}{|c|}{ Mean } & \multirow{2}{*}{ Quadrant } \\
\cline { 3 - 4 } & & Performance & Importance & \\
\hline 1 & Walking distance to bus stop & 2.690 & 3.955 & 3 \\
\hline 2 & Easiness to buy the ticket & 3.395 & 3.910 & 4 \\
\hline 3 & Ticket price & 3.505 & 3.830 & 4 \\
\hline \multirow{2}{*}{4} & $\begin{array}{l}\text { Availability of time table, bus } \\
\text { route in the bus stop }\end{array}$ & 3.130 & 4.215 & 2 \\
\hline 5 & Bus stop comfort & 2.695 & 4.220 & 1 \\
\hline 6 & Waiting time in the bus stop & 2.405 & 4.105 & 3 \\
\hline 7 & Bus-stop'screw service & 3.160 & 3.960 & 4 \\
\hline 8 & Bus stop cleanliness & 2.955 & 4.070 & 4 \\
\hline 9 & Keepingpunctuality & 2.345 & 4.385 & 1 \\
\hline 10 & On buscomfort & 2.745 & 4.325 & 1 \\
\hline 11 & Bus crew service & 3.205 & 3.945 & 4 \\
\hline 12 & Secure from crime & 3.350 & 4.425 & 2 \\
\hline 13 & Trip safety & 3.190 & 4.415 & 2 \\
\hline 14 & Travel time & 2.630 & 4.295 & 1 \\
\hline 15 & Route/bus transfer & 3.025 & 3.930 & 4 \\
\hline 16 & Operating time & 3.175 & 3.920 & 4 \\
\hline 17 & Accessibility & 2.680 & 4.215 & 1 \\
\hline 18 & $\begin{array}{l}\text { Governmentinstantiate by using } \\
\text { public transportation }\end{array}$ & 2.350 & 3.805 & 3 \\
\hline 19 & Safe for childpassenger & 2.505 & 4.225 & 1 \\
\hline & Total & 55.135 & 78.150 & \\
\hline & & 2.902 & 4.113 & \\
\hline
\end{tabular}

The intersection in the IPA is determined using the mean level of importance at 4.113 and the mean level of performance 2.902. In quadrant I, non-passengers reveal the attributes as very important, but the performances of Trans Jogja are must be improved significantly. Thus, further improvement efforts must be focused here. There are six attributes that fall into this quadrant:
1. Keeping punctuality (9)

2. Safe for child passenger (19)

3. Travel time (14)

4. On bus comfort (10)

5. Accessibility (17)

6. Bus stop comfort (5) 


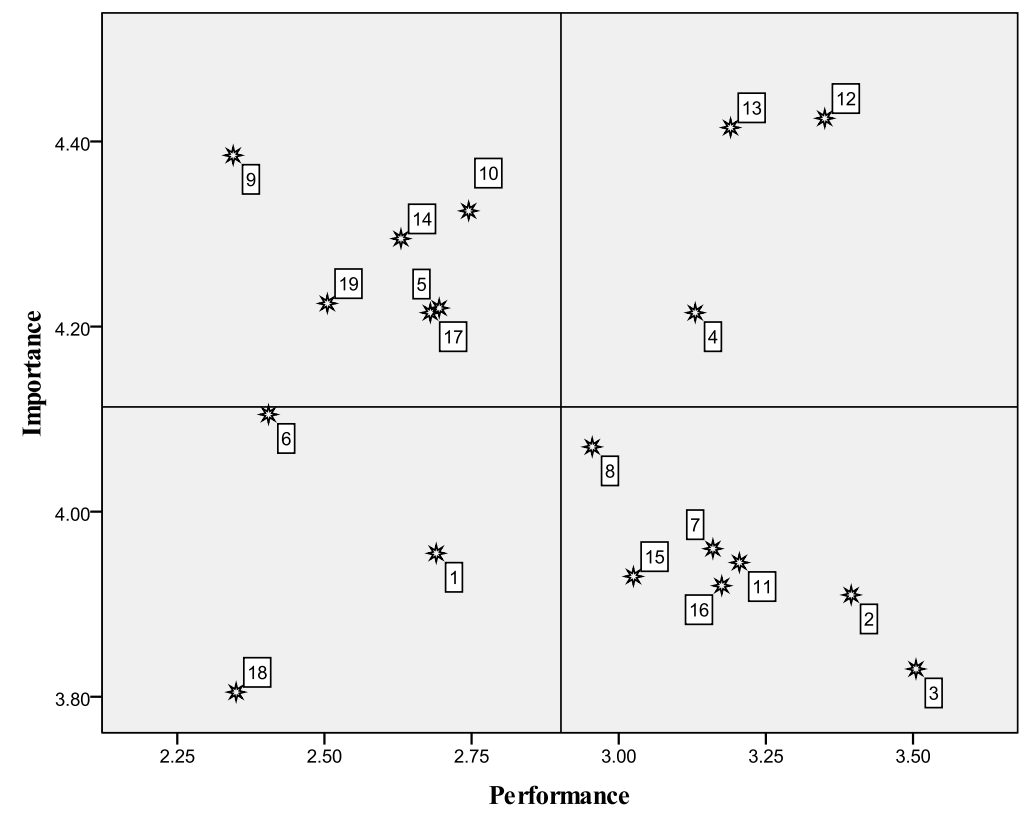

Fig. 3.Trans Jogja Non Passenger IPA Grid

However, some attributes are important to build non passengers' trust in moving to Trans Jogja. These attributes have already performed excellently and must be kept in high level performance because non passengers satisfy with the recent performance. Attributes such as availability of time table, bus route in bus stop (4), secure from crime (12), and trip safety (13), placed in quadrant II, are perceived to be very important and satisfied from the non-passenger's point of view. All these attributes must be kept up the good work in maintaining or delighting their passengers, as otherwise, these benefits might risk falling into the first quadrant.

Some of the attributes that literally categorized as low priority in quadrant III are walking distance to bus stop (1), waiting time in the bus stop (6), and government instantiate by using public transportation (18). These attributes are considered unimportant, however, the performance is deemed in average level.

Seven attributes located in quadrant IV, i.e. easiness to buy the ticket (2), ticket price (3), bus-stop's crew service (7), bus stop cleanliness (8), bus crew service (11), route/bus transfer (15), and operating time (16) that are considered as of unimportant with excellent performance. Non passengers are very pleased with these Trans Jogja attributes performance, therefore, all of the effort to improve these attributes will be useless because non passengers are already satisfied. Trans Jogja management must consider allocating their resources to develop those in Quadrant I to obtain higher benefit, rather than taking into account quadrant IV.

\section{The Main Priorities Enhancing Trans Jogja Based on Passenger's and Non Passenger's Perception}

This research study managed to provide useful recommendations for Trans Jogja operator, government or policy makers for developing public transportation strategies in the future. The IPA grid reveals areas of strategic focus, i.e., first quadrants with findings in this area that require the greatest attention. Also, to be highlighted in this research that pay attention on nonpassenger suggestion will attract new comer and can be expected reducing private car population. Seven attributes from passenger and six attributes from nonpassenger are revealed as main priority for improving Trans Jogja serviceability. Operator should pay more attention in these attributes to keep present passenger's trust and attract new passengers. The main priorities for developing Trans Jogja can be seen in Table 3.

Table 3. The Main Priorities for Enhancing Trans Jogja

\begin{tabular}{|l|c|c|}
\hline $\begin{array}{c}\text { PerformanceAtribu } \\
\text { ttes }\end{array}$ & $\begin{array}{c}\text { Passenger'sPrio } \\
\text { rity }\end{array}$ & $\begin{array}{c}\text { Non } \\
\text { Passenger'sPrio } \\
\text { rity }\end{array}$ \\
\hline Keepingpunctuality & 1 & 1 \\
\hline $\begin{array}{l}\text { Waiting time in the } \\
\text { bus stop }\end{array}$ & 2 & - \\
\hline On buscomfort & 3 & 4 \\
\hline $\begin{array}{l}\text { Safe for } \\
\text { childpassenger }\end{array}$ & 4 & 2 \\
\hline Bus stop comfort & 5 & 6 \\
\hline Accessibility & 6 & 5 \\
\hline Travel time & 7 & 3 \\
\hline
\end{tabular}

Both passengers and non-passenger primary concern is punctuality. They are not satisfied with this attribute. Therefore, passengers stated that waiting time in the bus stop is another attribute which must be improved. Time scheduling should be launched to control arrivingdeparting Trans Jogja on the bus stop. Also, time 
scheduling will be expected to create trust to Trans Jogja to both passengers and non passengers, because passengers are not tolerant with unpredictable waiting time in the bus stop.

Besides that, bus stop's serviceability should be improved by size/dimension enlargement, addition and deployment in to main points, and improvement of facilities for person with physically disabilities. In order to cut the waiting time and improve on bus comfort, the number of buses must be added with the new buses, and also the project to repair old buses must be conducted. Recently, 64 buses are operated to cover 4 routes and $32.5 \mathrm{~km} 2$ areas of Yogyakarta city, it is considered not sufficient. The routes should be developed to reach suburban and some supporting areas around the city. Most of people come from country sides during week-day for working and studying. Besides that, as one of popular tourist destination, the bus routes need to connect tourist destination areas located in country-side.

\section{Conclusion}

In this paper, the IPA technique is discussed and applied to measure Trans Jogja performance from the perspective of passenger and non-passenger to find main priority for the allocation of resources. A set of survey was developed to survey both passenger's and nonpassenger's perceptions to identify areas of importance and areas of satisfaction/dissatisfaction, which then enable government/providers to strategically identify focus areas to improve urban public transportation services. IPA is a strategic tool that can quickly enable Trans Jogja operator and government to understand public's needs and wants (important prioritization areas) and also to assess public's satisfaction rather than relying on performance indicators alone.

The results of this research reveal that Trans Jogja operator and decision maker/government must focus and allocate their resources to improve Trans Jogja system on the following attributes that fall in the first quadrant: a) keep punctuality, b) shorten waiting time in the bus stop, c) improve bus comfort, d) provide safety for child passenger, e) improve bus stop comfort, f) create new bus route to enlarge accessibility, and g) shorten bus travel time. In the fourth quadrant, there is an overemphasis in the operator's allocation of resources on attributes that are deemed to be unimportant and it is considered to reallocate their resources to first quadrant. This research considers investigating public's perspective on the importance and performance of attributes in terms of Trans Jogja services (demand side), but it can be performed a similar research to study attributes considering important from operator's point of view (supply side).

\section{References}

1. Z. Idris, J. Din.Tek. Spl, 9, 189-196, (2009)

2. J. Martilla,J. James, J. Market, 41 (1), 77-79, (1977)
3. M. S. Wong, N. Hideki, P. George, J. Theo. and Appl. Elect. Com. Res., 6, 17-30, (2011) 